\title{
Astronomical Sites in the Ukraine: Current Status and Problems of Preservation
}

I. B. Vavilova ${ }^{1}$, V. G. Karetnikov², A. A. Konovalenko ${ }^{3}$, O. O. Logvinenko ${ }^{4}$, G. I. Pinigin ${ }^{5}$, N. V. Steshenko ${ }^{6}$,

V. K. Tarady ${ }^{7}$ and Ya. S. Yatskiv ${ }^{8}$

${ }^{1}$ Astronomical Observatory, Shevchenko National University, 3 Observatorna St., Kyiv, 254053 Ukraine

${ }^{2}$ Astronomical Observatory, Odesa State University, Shevchenko Park, Odesa, 270014 Ukraine

${ }^{3}$ Institute of Radio Astronomy of the NASU, 4 Chervonopraporna St., Kharkiv, 310002 Ukraine

${ }^{4}$ Astronomical Observatory, Lviv University, 8 Kyryla i Mephodija St., Lviv, 290005 Ukraine

${ }^{5}$ Astronomical Observatory, 1 Observatorna St., Mykolaiv, 327030 Ukraine

${ }^{6}$ Crimean Astrophysical Observatory, Naukove, Bakhchisarai, Crimea, 334413 Ukraine

${ }^{7}$ International Centre of Astronomical and Medical-Ecological Research, Golosiiv, Kyiv, 252022 Ukraine

${ }^{8}$ Main Astronomical Observatory of the NASU, Golosiiv, Kyiv, 252022 Ukraine

\begin{abstract}
The current status of optical and radio astronomical sites in the Ukraine and the problems of preservation are briefly reviewed. The problems of light pollution and the influence of technology can be solved using scientific and engineering methods. However the main problem of preservation is the economic one of maintaining infrastructure.
\end{abstract}

\section{Introduction}

There are two types of astronomical observatory in the Ukraine. Observatories of the first type were formed in the eighteenth and nineteenth centuries. Being now located in the big cities of Kyiv, Kharkiv, Lviv, Mykolaiv, Odesa and Poltava, these observatories are not involved in modern observational programmes but are used as administrative centres, and for publicity and training purposes. They have observatories located in suburbs and equipped with small optical telescopes.

The development of astrophysics in the twentieth century has resulted in the formation of a second class of observatory in the Ukraine, which includes the following: the Main Astronomical Observatory (MAO) in Golosiiv, Kyiv, the Crimean Astrophysical Observatory ( $\mathrm{CrAO}$ ) in Naukove, Crimea, the Observatory of the Institute of Radio Astronomy (IRA) in Hrakovo, Kharkiv, and the high-altitude observatory at the Peak Terskol (North Caucasus, Russia), which 
was founded by MAO in 1974 (now the "International Center of Astronomical and Medical-Ecological Research"). The astronomical sites in the Ukraine are listed in Table 1 and classified according to the above scheme.

Table 1. Astronomical Sites in the Ukraine.

\begin{tabular}{|c|c|c|c|c|c|c|}
\hline Title & $\begin{array}{c}\text { Founded } \\
\text { in }\end{array}$ & $\begin{array}{l}\text { Type } \\
(1 / 2)\end{array}$ & $\begin{array}{c}\text { Situated } \\
\text { in } \\
\end{array}$ & $\begin{array}{r}\text { Longitude } \\
\text { Latitude }\end{array}$ & $\begin{array}{l}\text { Altitude } \\
(\mathrm{m})\end{array}$ & $\begin{array}{r}\text { Field of } \\
\text { Research }\end{array}$ \\
\hline $\begin{array}{l}\text { Astronomical } \\
\text { Observatory, } \\
\text { Lviv State } \\
\text { University }\end{array}$ & 1769 & 1 & Lviv & $\begin{array}{l}24^{\circ} 01.8^{\prime} \\
49^{\circ} 50.0^{\prime}\end{array}$ & 330 & $\begin{array}{c}\text { solar physics } \\
\text { astrophysics }\end{array}$ \\
\hline $\begin{array}{l}\text { Astronomical } \\
\text { Observatory, } \\
\text { Kharkiv State } \\
\text { University }\end{array}$ & 1808 & 1 & Kharkiv & $\begin{array}{l}36^{\circ} 13.9^{\prime} \\
50^{\circ} 00.2\end{array}$ & 138 & $\begin{array}{r}\text { astrometry } \\
\text { astrophysics }\end{array}$ \\
\hline $\begin{array}{l}\text { Mykolaiv } \\
\text { Astronomical } \\
\text { Observatory }\end{array}$ & 1821 & 1 & Mykolaiv & $\begin{array}{l}31^{\circ} 58.5^{\prime} \\
46^{\circ} 58.3^{\prime}\end{array}$ & 54 & astrometry \\
\hline $\begin{array}{l}\text { Astronomical } \\
\text { Observatory, } \\
\text { National } \\
\text { University }\end{array}$ & 1845 & 1 & Kyiv & $\begin{array}{l}30^{\circ} 29.9^{\prime} \\
50^{\circ} 27.2^{\prime}\end{array}$ & 184 & $\begin{array}{r}\text { astrometry } \\
\text { solar physics } \\
\text { astrophysics }\end{array}$ \\
\hline $\begin{array}{l}\text { Astronomical } \\
\text { Observatory, } \\
\text { Odesa State } \\
\text { University }\end{array}$ & 1865 & 1 & Odesa & $\begin{array}{l}30^{\circ} 45.5^{\prime} \\
46^{\circ} 28.6^{\prime}\end{array}$ & 60 & $\begin{array}{r}\text { astrometry } \\
\text { astrophysics }\end{array}$ \\
\hline $\begin{array}{l}\text { Gravimetrical } \\
\text { Observatory }\end{array}$ & 1926 & 1 & Poltava & $\begin{array}{l}34^{\circ} 32.8^{\prime} \\
49^{\circ} 36.3^{\prime}\end{array}$ & 151 & astrometry \\
\hline $\begin{array}{l}\text { Main } \\
\text { Astronomical } \\
\text { Observatory }\end{array}$ & 1944 & 2 & $\begin{array}{c}\text { Golosiiv, } \\
\text { Kyiv }\end{array}$ & $\begin{array}{l}30^{\circ} 30.4^{\prime} \\
50^{\circ} 21.9^{\prime}\end{array}$ & 188 & $\begin{array}{r}\text { solar physics } \\
\text { astrophysics } \\
\text { astrometry }\end{array}$ \\
\hline $\begin{array}{l}\text { Crimean } \\
\text { Astrophysical } \\
\text { Observatory }\end{array}$ & 1945 & 2 & $\begin{array}{c}\text { Naukove, } \\
\text { Peninsula } \\
\text { Crimea }\end{array}$ & $\begin{array}{l}34^{\circ} 01.0^{\prime} \\
44^{\circ} 43.6^{\prime}\end{array}$ & 600 & $\begin{array}{r}\text { astrophysics } \\
\text { solar physics } \\
\text { radio astronomy }\end{array}$ \\
\hline $\begin{array}{l}\text { High- } \\
\text { Altitude } \\
\text { Observatory } \\
\text { at the Peak } \\
\text { Terskol }\end{array}$ & 1974 & 2 & $\begin{array}{c}\text { Peak } \\
\text { Terskol } \\
\text { North } \\
\text { Caucasus, } \\
\text { Russia }\end{array}$ & $\begin{array}{l}42^{\circ} 30.0^{\prime} \\
43^{\circ} 16.4^{\prime}\end{array}$ & 3100 & $\begin{array}{l}\text { astrophysics } \\
\text { solar physics }\end{array}$ \\
\hline $\begin{array}{l}\text { Observatory } \\
\text { of Institute } \\
\text { of Radio } \\
\text { Astronomy }\end{array}$ & 1985 & 2 & $\begin{array}{l}\text { Hrakovo, } \\
\text { Kharkiv }\end{array}$ & $\begin{array}{l}36^{\circ} 56.0^{\prime} \\
49^{\circ} 38.0^{\prime}\end{array}$ & 150 & $\begin{array}{r}\text { radio } \\
\text { astronomy }\end{array}$ \\
\hline
\end{tabular}

\section{Optical Astronomy and Light Pollution}

\subsection{Positional Astronomy}

University observatories in Kyiv, Kharkiv, Odesa (Table 1) were initially equipped with meridian instruments for the determination of star positions and were involved in the international programmes AGK3R, FK4, SRS etc. These observatories had practically finished their work by the 1990 s. In 1995 , the new auto- 
matic Axial Meridian Circle (AMC) equipped with CCDs was built in Mykolaiv Observatory (a former department of Pulkovo Observatory). The parameters of AMC are as follows: $D=180 \mathrm{~mm}$ and $F=2480 \mathrm{~mm}$ for the main telescope, and $D=180 \mathrm{~mm}$ and $F=12360 \mathrm{~mm}$ for the collimators. This unique meridian instrument of axial type has been recently used for observations of the HIPPARCOS stars. At present, AMC is in the process of an upgrade that will allow the HIPPARCOS frame to be extended to objects down to $16^{m}$. The main problem of preserving the Mykolaiv site is to reduce light pollution, so that the number of useful nights of observing (now 116 per year) does not decrease further.

\subsection{Optical Astronomy with Telescopes of Small Size}

Observational stations of university observatories (Lisnyky near Kyiv, Hrakovo near Kharkiv, Maiaky near Odesa and Briukhovychi near Lviv) are equipped with small reflectors $(D=12,5$ to $100 \mathrm{~cm})$, which are actively engaged in observations of comets, meteors, minor planets, satellites of planets and artificial satellites (Vovchyk, Blagodyr \& Logvynenko 2001). In addition, photometric and polarimetric observations of stars are carried out with telescopes (AMT-3 with $D=48 \mathrm{~cm}$ ) at the Maiaky and Briukhovychi sites. The average number of clear nights for photometric observations is about 100 per year. Results of observations of Night Sky Brightness (NSB) and atmospheric transparency, which have been carried out at the Maiaky site during the years 1968-1997 are presented in Tables 2 and 3 . The NSB $\left(\mathrm{erg} / \mathrm{cm}^{2} \cdot \mathrm{sec} \cdot \mathrm{A} \cdot \mathrm{ster}^{2}\right)$ was measured at $\lambda=0.36 \mathrm{~nm}$ and $\lambda=0.58 \mathrm{~nm}$ after evening twilight (ev) or before morning twilight (mo), when the Sun was $17-20^{\circ}$ below the horizon. Positive values of zenith distance are towards the Sun.

Table 2. Night Sky Brightness $\left(\mathrm{erg} / \mathrm{cm}^{2} \cdot \mathrm{sec} \cdot \mathrm{A} \cdot \mathrm{ster}^{2}\right)$ as a function of zenith distance at the Maiaky site.

\begin{tabular}{crrrrrrrrrr}
\hline & \multicolumn{9}{c}{$\lambda=0.36 \mathrm{~nm}$} & \multicolumn{4}{c}{$\lambda=0.58 \mathrm{~nm}$} \\
Date & $60^{\circ}$ & $30^{\circ}$ & $0^{\circ}$ & $-30^{\circ}$ & $-60^{\circ}$ & $60^{\circ}$ & $30^{\circ}$ & $0^{\circ}$ & $-30^{\circ}$ & $-60^{\circ}$ \\
\hline $27.06 .68 \mathrm{ev}$ & -6.34 & -6.46 & -6.50 & -6.49 & -6.42 & -6.05 & -6.07 & -6.18 & -6.16 & -6.12 \\
$15.12 .68 \mathrm{ev}$ & -6.29 & -6.32 & -6.34 & -6.38 & -6.39 & -6.05 & -6.17 & -6.19 & -6.20 & -6.09 \\
$13.10 .69 \mathrm{mo}$ & -6.52 & -6.60 & -6.58 & -6.62 & -6.65 & -6.00 & -6.19 & -6.21 & -6.22 & -6.16 \\
$13.10 .69 \mathrm{ev}$ & -6.54 & -6.62 & -6.64 & -6.63 & -6.58 & -6.06 & -6.23 & -6.18 & -6.23 & -6.11 \\
\hline Av. 1968-69 & -6.42 & -6.50 & -6.52 & -6.53 & -6.51 & -6.04 & -6.16 & -6.19 & -6.20 & -6.12 \\
\hline $08.08 .94 \mathrm{mo}$ & -6.21 & -6.45 & -6.55 & -6.58 & -6.54 & -5.85 & -6.14 & -6.23 & -6.22 & -6.10 \\
$08.08 .94 \mathrm{ev}$ & -6.36 & -6.57 & -6.62 & -6.56 & -6.48 & -5.68 & -6.13 & -6.24 & -6.17 & -6.04 \\
$03.07 .97 \mathrm{mo}$ & -6.00 & -6.35 & -6.38 & -6.38 & -6.34 & -5.80 & -6.17 & -6.26 & -6.18 & -5.93 \\
$03.07 .97 \mathrm{ev}$ & -6.06 & -6.40 & -6.48 & -6.40 & -6.28 & -5.62 & -6.05 & -6.11 & -6.08 & -6.03 \\
\hline Av. 1994-97 & -6.16 & -6.44 & -6.51 & -6.48 & -6.41 & -5.74 & -6.12 & -6.21 & -6.16 & -6.02 \\
\hline
\end{tabular}

Comparison of the NSB values measured during 1968-69 and 1994-97 demonstrates a significant variation during the 20 years at this site. The average NSB value has increased by about $0.1 \mathrm{mag}$ at both wavelengths during this period. It can also be seen that the difference in NSB between zenith distances $0^{\circ}$ and $60^{\circ}$ was $0.1 \mathrm{mag}$ in $1968-69$ and $0.35 \mathrm{mag}$ in $1994-97$ at $\lambda=0.36 \mathrm{~nm}$ and $0.15 \mathrm{mag}$ and $0.47 \mathrm{mag}$ at $\lambda=0.58 \mathrm{~nm}$, respectively. This means that these differences increase with increasing wavelength and there is a slight zenith distance effect. 
Table 3. Atmospheric transparency $P(\lambda)$ deduced at the Maiaky site during the years 1967-1997.

\begin{tabular}{cccccc}
\hline Date & $\lambda 0.36 \mathrm{~nm}$ & $\lambda 0.75 \mathrm{~nm}$ & Date & $\lambda 0.36 \mathrm{~nm}$ & $\lambda 0.75 \mathrm{~nm}$ \\
\hline $11 / 12.12 .1967$ & 0.44 & 0.71 & $29 / 30.06 .1994$ & 0.51 & 0.82 \\
$20 / 21.07 .1968$ & 0.42 & 0.66 & $09 / 10.08 .1994$ & 0.27 & 0.68 \\
$14 / 15.12 .1968$ & 0.51 & 0.72 & $22 / 23.08 .1995$ & 0.47 & 0.79 \\
$08 / 09.07 .1969$ & 0.48 & 0.75 & $19 / 20.09 .1995$ & 0.54 & 0.98 \\
$05 / 06.11 .1969$ & 0.44 & 0.69 & $02 / 03.07 .1997$ & 0.53 & 0.91 \\
$24 / 25.08 .1993$ & 0.28 & 0.66 & $07 / 08.09 .1997$ & 0.45 & 0.79 \\
\hline
\end{tabular}

One can see from Table 3 that transparency values increased during 1968-97. The dispersion of these values also indicates degradation of the Maiaky site. The situation is similar for all the suburban observational sites of the Ukraine.

\subsection{Optical Astronomy with Telescopes of Medium Size}

The Ukraine has optical telescopes of medium size, situated in $\mathrm{CrAO}$ (the 2.6$\mathrm{m}$ Shajn telescope, two 1.25-m telescopes) and at the Peak Terskol (the 2-m telescope). These instruments are used for investigations of stars of various types, stellar systems, galaxies and Solar system bodies. Table 4 gives the results of measuring the extinction coefficients at these sites in comparison with MAO (Yatskiv 1999).

Table 4. Coefficients of extinction in the UBV system for the Peak Terscol, CrAO and MAO sites.

\begin{tabular}{crrrr}
\hline System & $\begin{array}{r}\text { Peak Terskol } \\
\text { North Caucasus } \\
\text { mean value }\end{array}$ & $\begin{array}{r}\text { Peak Terskol } \\
\text { North Caucasus } \\
\text { best value }\end{array}$ & $\begin{array}{r}\text { CrAO, } \\
\text { Crimea } \\
\text { best value }\end{array}$ & $\begin{array}{r}\text { Golosiiv, Kyiv } \\
\text { best value }\end{array}$ \\
\hline $\mathrm{U}$ & $0^{m} .55$ & $0^{m} .36$ & $0^{m} .65$ & $1^{m} .03$ \\
$\mathrm{~B}$ & $0^{m} .28$ & $0^{m} .18$ & $0^{m} .35$ & $0^{m} .56$ \\
$\mathrm{~V}$ & $0^{m} .22$ & $0^{m} .11$ & $0^{m} .22$ & $0^{m} .50$ \\
\hline
\end{tabular}

The 2.6-m Shajn telescope (Cassegrain system), which began operations in 1960 , is now the best equipped telescope in the Ukraine. There are about of 150 nights per year with moderate seeing. The photometric parameters of NSB in Crimea have been studied in detail by Lyutyi and Sharov (1982). They found that the B-V colour index of the night sky increases with the B-V colour extinction of the atmosphere, and there is no relation between NSB and atmospheric extinction.

The 2-m Ritchey-Chretien-Coude telescope has been in operation since 1995. The low atmospheric water vapour content and the high atmospheric transparency in the UV and IR wavebands allow us to infer that the Peak Terskol is one of the best observational sites in Europe (see Table 4). The mean seeing at the site is $\sim 1$ arcsec. The average number of clear night hours is $\sim 1000$ per year. Because of economic problems, the observational programme at the Peak Terskol is not regular. To increase the effectiveness of the 2-m telescope, a 
new CCD and fast telecommunication channel are needed. These will allow the instrument to take its part in international research projects.

\section{Radio Astronomy and the Interference Struggle}

The Institute of Radio Astronomy (IRA) of the NASU possesses the world's largest decametric radio telescope, the UTR-2 Array, with a frequency range of $8-32 \mathrm{MHz}$ (Braude et al. 1978). Its huge effective area of $150,000 \mathrm{~m}^{2}$ is more than the total effective area of all other existing radio telescopes. At a distance of $43 \mathrm{~km}$ from UTR-2, the decametric VLBI system URAN was built (Megn et al. 1997). It gives a highest angular resolution for decameter waves at the arcsecond level. Various investigations have been carried out with these instruments over almost 30 years, covering practically all objects in the Universe including the near-Earth vicinity, Solar system and Galaxy and more distant objects such as radio galaxies and quasars. Many priority results were obtained, confirming the great value of decametric radio astronomy.

The principal problem for decametric radio astronomy is the negative influence of transmissions from many broadcasting and other radio stations. It is not possible to regulate or restrict their operation. Because of the methods of decametric radio astronomy, the preservation of radio astronomical sites includes such matters as:

1. Creation of interference-immune high dynamic-range receiver systems, and

2. Use of special observational methods and data processing (Konovalenko et al. 1996).

Furthermore, it is important to carry out long-term interference monitoring. Fig. 1 illustrates some examples of such monitoring for intense interference in the UTR-2 frequency range. The results of deep interference monitoring in a relatively narrow band for very weak interference signals are shown in Fig. 2 (Konovalenko et al. 1997). According to these experiments, it can been concluded that interference pollution has not increased during the last decades, on the whole. More significant variations of interference level occur according to the Solar activity, the season, the day of the week and the time of day. Furthermore, even for this difficult decametric range there are rather clear frequency windows. This allows the reception of radio astronomy signals even in the presence of interference. Such experience of UTR-2 operations could be useful for the creation of a new generation of decametric radio telescope.

In recent years the IRA has been carrying out work to upgrade the centimeterdecameter waveband RT-70 antenna at Evpatoria, Ukraine. To preserve operations in the presence of rising levels of interference pollution, special filters were installed on the RT-70 for interference rejection near $325 \mathrm{MHz}$. The future direction of decametric and hectometeric radio astronomy is connected with radio telescopes outside the Earth ionosphere. This will allow us to exclude completely the strong influence of the ionosphere as well as that of terrestrial interference. There are some excellent spaceborne extremely low frequency projects (see, for example, Weiler et al. 1988), in which Ukrainian radio astronomers are actively involved. 


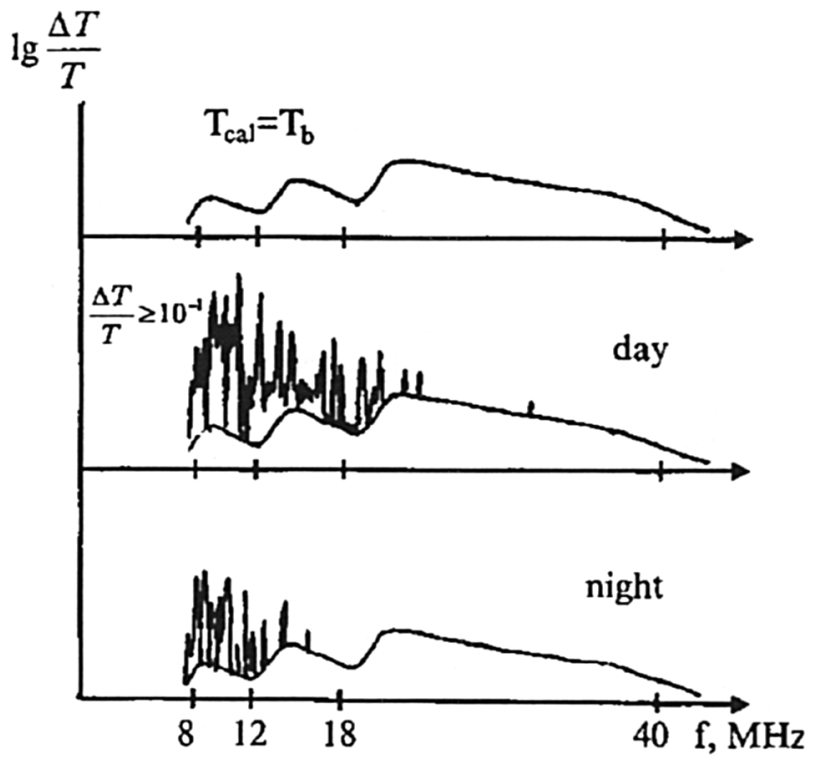

Figure 1. Interference monitoring in the operating range of UTR-2 (calibration spectrum is at the top of Figure).

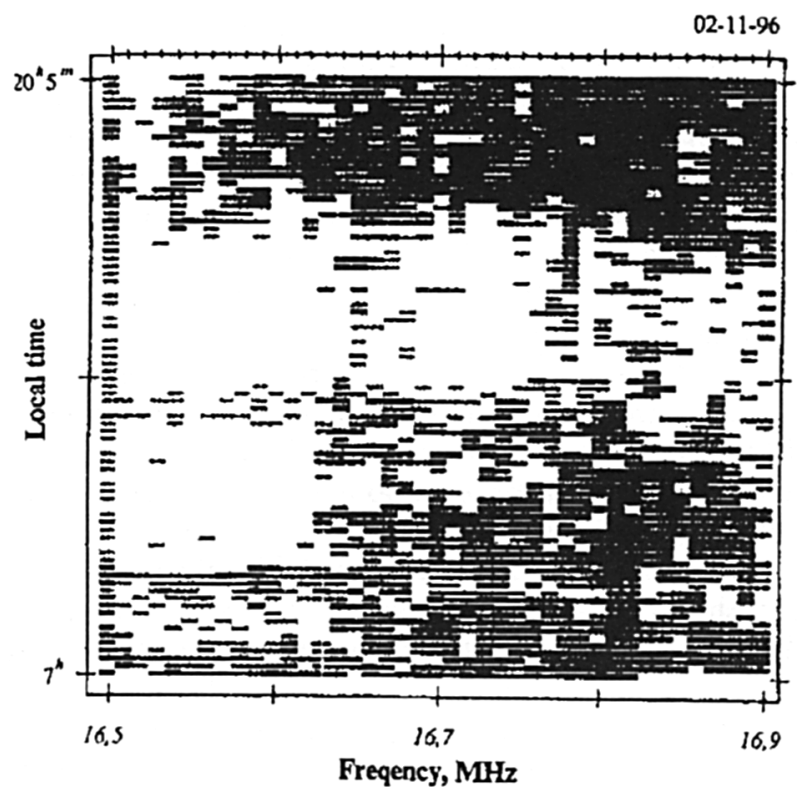

Figure 2. Monitoring of weak hindering signals during night time near $16,7 \mathrm{MHz}$. White corresponds to interference with intensity $30 \mathrm{~dB}$ lower than the background level. 


\section{Conclusion}

There are several tasks in preserving astronomical sites in the Ukraine. The problems of light pollution and the influence of technology can be solved by using appropriate scientific methods (some of them are mentioned in Paper). However, the main problem of preservation is connected with the economical situation. Most of the observating sites (CrAO, RT-22, observatory at the Peak Terskol, MAO etc.) are built as self-contained systems with their own water and energy supply, school and kindergarden. Thus, they are need comparatively large budgets. The preservation of these sites depends, in the first instance, on improving the level of their infrastructure.

As the first step in preserving these sites, the Ukrainian Astronomical Association has recommended the government of the Ukraine to give some observational sites the status of "National Property". This status is a guarantee of additional state funding. Such a status was given in 1999 to the following facilities:

- Radio telescope UTR-2 with the URAN interferometric system (IRA);

- 2.6-m telescope, RT-22, Solar tower telescope, satellite laser-ranging station Cimeiz-1873, gamma-telescope GT-48 (CrAO);

- Coherent-optical image processor of the Astronomical Observatory of Kharkiv University;

- Axial Meridian Circle (Mykolaiv AO).

Acknowledgments. I.B. Vavilova thanks the IAU for financial support to attend such an important symposium.

\section{References}

Braude, S. Ya., Megn, A. V. \& Sodin, L. G. 1978, Antennas, 26, 3

Konovalenko, A.A. 1996, in Large antennas in radio astronomy, ESTEC, 1996, 139

Konovalenko, A.A., Sokolov, K. P. \& Stepkin, S. V. 1997, Radio Physics \& Radio Astronomy, 2, 188

Vovchyk, J., Blagodyr, J. \& Logvynenko, O.O. 2001, in these proceedings

Lyutyi, V.M. \& Sharov, A.S. 1982, Astern. Hz., 59, 174

Megn, A. V., Braude, S. Ya., Rashkovskij, S. L., et al. 1997, Radio Physics \& Radio Astronomy, 2, 385

Yatskiv, Ya.S. \& Kondratyuk, R.R. 1999, personal communication

Weiler, K.W., et al. 1988, A\&A, 195, 372 